\title{
HYBRID WORLDS: Societal and Ethical Challenges
}

Proceedings of ICRES 2018 - the third edition of International Conference series on Robot Ethics and Standards, New York, USA, 20 - 21 August 2018.

\section{Preface}

Hybrid worlds is the proceedings book of ICRES 2018 - the third edition of International Conference series on Robot Ethics and Standards, organized by CLAWAR Association in collaboration with the Rensselaer Polytechnic Institute (RPI) within the premises of RPI in Troy, New York, USA during 20 - 21 August 2018.

ICRES 2018 brings new developments and new research findings in robot ethics and ethical issues of robotic and associated technologies. The topics covered include artificial intelligence, artificial moral agents and moral decisions, robot companionship and consequent ethical risks, and ethical obligations.

The ICRES 2018 conference includes a total of 22 articles, including four plenary lectures, from 11 countries. This number has been arrived at through rigorous review of initial submissions, where each paper initially submitted has received on average three reviews.

The editors would like to thank members of the International Scientific Committee and National Organising Committee for their efforts in reviewing the submitted articles, and the authors in addressing the comments and suggestions of the reviewers in their final submissions. It is believed that the ICRES 2018 proceedings will be a valuable source of reference for research and development in the rapidly growing area of robotics and associated technologies.

S. Bringsjord, M. O. Tokhi, M. I. A. Ferreira and N. S. Govindarajulu 